\title{
EPIDEMIOLOGICAL PROFILE OF BREAST CANCER IN MEN IN BRAZIL BETWEEN 2008 AND 2018
}

Felipe Z. Pereira', Karla O. Elesbão', Victória O. Prados, Fabiane A. Carvalho

${ }^{1}$ Centro Universitário de Anápolis (UniEVANGÉLICA) - Anápolis (GO), Brazil.

Objectives: To outline the epidemiological profile of breast cancer in men based on variables as mortality rate, age, race, hospitalization and total cost. Methods: Ecological study, population-based and cross-sectional design. The total number of cases and deaths occurred in Brazil for male breast cancer between january 2008 and 2018. The data were collected from the Hospital Information System of SUS (SIH/SUS). Initially, descriptive statistics were performed and then the data were analyzed by ratio scale and relative frequency. Results: The total number of cases of malignancy reported in Brazil, between the mentioned period, was 4,090. The mortality rate presented progressive increase, with an average percentage of $7.5 \%$. In relation to age, the group of 35 to 70 years old had the highest number of patients, especially the young people aged 60 to 70 years, who represented $23 \%$ of the total. The third age also presented more than $25 \%$ of the deaths due to neoplasia. Whites and browns were the most affected, accounting for $53 \%$ and $40 \%$ of the total, respectively. Most of the patients were treated in private institutions, which, in turn, had a 3.5 times higher expenditure when compared to the public system. Conclusions: This study verified an increase in the number of breast cancer cases in men in Brazil, as well as a rise in the death rate due to this disease. The finding by age group shows a peak in young adults, which coincides with the world literature, which shows a predominance between 60 and 70 years. In contrast, ethnicity analysis in this study shows that whites and browns account for the majority of those afflicted, while the world standard shows blacks as the most affected. The higher expenditures by private health agencies may be hypothetically justified by the fact that they have better conditions of medical and hospital care for these patients. Nonetheless, it should be taken into account that SUS often directs patients to private institutions because they do not have adequate and adequate infrastructure. Given the above, it is evident the need for studies aimed at a better understanding of this disease, since late diagnosis, as reported, leads to higher death rates, as well as increasing expenditures of government and private institutions with the treatment of patients. 